\title{
Corrigendum: A Probabilistic Framework for Decoding Behavior From in vivo Calcium Imaging Data
}

\author{
Guillaume Etter*, Frederic Manseau and Sylvain Williams* \\ Douglas Mental Health University Institute, McGill University, Montreal, QC, Canada
}

Keywords: calcium imaging, decoding, bayesian inference, hippocampus, spatial coding

\section{A Corrigendum on}

A Probabilistic Framework for Decoding Behavior From in vivo Calcium Imaging Data by Etter, G., Manseau, F., and Williams, S. (2020) Front. Neural Circuits 14:19. doi: $10.3389 /$ fncir.2020.00019

In the original article, there were errors in several equations. Some terms were flipped or omitted.

Corrections have been made to Results, Extracting Probability Values in a Bayesian Context, Equations 1 and 2, and Results, Decoding Behavior Using Activity From Multiple Neurons, Equations

OPEN ACCESS

Approved by: Frontiers Editorial Office Frontiers Media SA, Switzerland

*Correspondence: Guillaume Etter etterguillaume@gmail.com Sylvain Williams sylvain.williams@mcgill.ca

Received: 13 November 2020 Accepted: 16 November 2020 Published: 11 December 2020

Citation:

Etter G, Manseau F and Williams S (2020) Corrigendum: A Probabilistic Framework for Decoding Behavior From in vivo Calcium Imaging Data.

Front. Neural Circuits 14:629162. doi: 10.3389/fncir.2020.629162 7 and 8.

The Corrected Equations are Shown Below:

Equation 1:

$$
P(\mathrm{~A})=\frac{\text { time active }}{\text { total time }}
$$

Equation 2:

$$
P\left(\mathrm{~S}_{i}\right)=\frac{\text { time in state } i}{\text { total time }}
$$

Equation 7:

$$
P(S \mid A)=\exp \left[\sum_{k=1}^{N} \log \left(1+\frac{P\left(A_{k} \mid S\right) \times P(S)}{P\left(A_{k}\right)}\right)-1\right]
$$


Equation 8:

$$
\hat{y}=\arg \max \exp \left[\sum_{k=1}^{N} \log \left(1+\frac{P\left(A_{k} \mid S\right) \times P(S)}{P\left(A_{k}\right)}\right)-1\right]
$$

The authors apologize for these errors and state that they do not change the scientific conclusions of the article in any way. The original article has been updated.

Copyright (C) 2020 Etter, Manseau and Williams. This is an open-access article distributed under the terms of the Creative Commons Attribution License (CC BY). The use, distribution or reproduction in other forums is permitted, provided the original author(s) and the copyright owner(s) are credited and that the original publication in this journal is cited, in accordance with accepted academic practice. No use, distribution or reproduction is permitted which does not comply with these terms. 